Article

\title{
Mortality of NBA Players: Risk Factors and Comparison with the General US Population
}

\author{
Jose A. Martínez ${ }^{1}$, Klaus Langohr ${ }^{2}$, Julián Felipo ${ }^{3}$ and Martí Casals ${ }^{4,5, *}$ \\ 1 Department of Business Economics, Universidad Politécnica de Cartagena, 30201 Cartagena, Spain; \\ josean.martinez@upct.es \\ 2 Department of Statistics and Operations Research, Universitat Politècnica de Catalunya/Barcelonatech, \\ 08034 Barcelona, Spain; klaus.langohr@upc.edu \\ 3 Newsroom, Basketball Departament, Mundo Deportivo, 08036 Barcelona, Spain; jfelipo@gmail.com \\ 4 Sport and Physical Activity Studies Centre (CEEAF), University of Vic-Central University of \\ Catalonia (UVic-UCC), 08500 Catalonia, Spain \\ 5 Medical Department, Futbol Club Barcelona, Barça Innovation Hub, 08028 Barcelona, Spain \\ * Correspondence: marti.casals1@umedicina.cat
}

Received: 7 January 2019; Accepted: 29 January 2019; Published: 1 February 2019

Featured Application: This is one of the first studies using such an extensive cohort of professional basketball players and Cox proportional hazards models, which takes into account left-truncation, i.e., late entry at the age of the players' NBA debuts. Results suggested that height and ethnicity are associated to mortality: White players and small players live longer. Our study is useful for devising strategies for health interventions and the proper allocation of resources with respect to the general population.

\begin{abstract}
Concerns have been raised recently by players' associations regarding the risk of death among retired players. Using a retrospective cohort study, we analyzed factors associated with the mortality of National Basketball Association (NBA) players and compared their life expectancy with that of the general population. We analyzed a cohort of 3985 players who participated in the NBA from its inception in 1946 to April 2015 (481 active and 3504 former players). We used the data for the 3504 former NBA players, of whom 687 (19.1\%) died before 15 April 2015, to study the elapsed time between the end of their NBA careers until death. Cox proportional hazards models were employed in the multivariate survival analysis. After adjusting for age at the end of the NBA career and calendar year, we found that mortality is associated with height and ethnicity. Taller players and African-American players had a higher instantaneous risk of death than shorter players or white players. In addition, the life expectancy of players (regardless of height and ethnicity) has increased since the inception of the NBA. This is one of the first studies using such an extensive cohort of professional basketball players and Cox proportional hazards models. Results confirmed that height is associated with mortality. In addition, ethnicity is also linked to mortality; white players and small players live longer. Our study is useful for devising strategies for health interventions and the proper allocation of resources with respect to the general population.
\end{abstract}

Keywords: prevention; survival analysis; basketball; mortality; NBA; sports medicine

\section{Introduction}

Active participation in sports is generally considered to be beneficial for health and well-being. Protecting the health of athletes is one of the priorities of the International Olympic Committee. The relationship between health and participation in sports has been studied from different perspectives with regard to mortality. Some recent studies have highlighted fatalities among players in 
professional leagues [1,2], and other studies have focused on the longevity and life expectancy (LE) of elite athletes [3-6].

Shortly after the 50th anniversary of the NBA, in 1996, a study was carried out to analyze mortality among NBA players [7] between 1946 and 1994, covering 2810 players, of whom 175 had died. Professional basketball players have had favorable mortality rates, despite adverse publicity following the (early) death of a very small number of players [7]. African-American players were shown to live nine years longer than their reference population group, and longer than white men in the general public [8]. Additionally, white NBA players live longer than the white US population, and longer than African-American players.

However, the literature also shows that basketball players may be at special risk of some fatal diseases. The incidence of sports-related sudden cardiac death (SCD) in the United States is highest among basketball players, and the most common cause of SCD in this population is hypertrophic cardiomyopathy [9]. In addition, research on the relationship between mortality and height has shown that height is positively associated with increased risk of cancer [10-12] and lower LE [6,13]. Moreover, height is positively associated with risk of venous thromboembolism [14], and professional basketball players have a higher risk of pulmonary embolism [15].

In recent years, there has been media concern about the early mortality of former NBA players [2,16,17], with numerous deaths in 2015 of well-known ex-professional basketball players before the age of 60 years. For instance, Moses Malone (aged 60 years), Darryl Dawkins (58), Jerome Kersey (52), Jack Haley (51), Christian Welp (50), and Anthony Mason (48) died between February and September of 2015. All of these players shared three similar features: They were $>2 \mathrm{~m}$ tall, had had a long NBA career, and had died from a heart/circulatory system-related event.

Some former players made public comments about this issue [16], such as Larry Bird (2.06 m; "I tell my wife all the time: You don't see many 7-footers $(2.13 \mathrm{~m})$ walking around at the age of 75") and Bill Walton ( $2.11 \mathrm{~m}$; “We athletes are our own worst enemies. We don't listen to our bodies, we don't listen to our doctors. We don't realize until later in life that health is everything").

These fatal events, along with societal concern, have provoked a reaction from the NBA and the scientific community. In 2016, the NBA and the NBA players' union embarked on a joint effort to provide health screening for retired players [16]. In addition, an initiative was started to analyze cardiac structure and function among 526 NBA players on active rosters for the 2013-2014 and 2014-2015 seasons, in order to provide a detailed understanding of normal and expected cardiac remodeling, i.e., structural and functional myocardial adaptation in response to sustained exercise [9].

There is much conflicting literature evidence on the mortality of basketball players, not only for heart-related conditions but for all diseases. Evidence on mortality and lifespan shows that the LE of team athletes practicing aerobic-anaerobic sports (such as basketball) is generally higher than in the general population $[3,6,18]$. Indeed, elite athletes have a higher LE than the general population $[19,20]$, and male elite athletes have been shown to survive 2-3 years longer than their male siblings [21]. Nevertheless, physical activity patterns including one or two sessions per week may be sufficient to reduce all-cause mortality, including cardiovascular disease (CVD) and cancer, regardless of adherence to prevailing physical activity guidelines [22]. Further, light to moderate amounts of exercise results in lower risk of CVD and early mortality than very extreme or very intense exercise [23,24].

Consequently, the aim of this research was two-fold: (1) To analyze the factors associated with mortality among former NBA players; and (2) to compare the LE of NBA players to that in the general population. To achieve these objectives, we analyzed data from 3985 players who participated in the NBA from its inception in 1946 to April 2015. 


\section{Materials and Methods}

\subsection{Design, Subjects, and Variables}

We performed a retrospective cohort study based on the records of all 3985 active and former NBA players. The cohort included all professional basketball athletes who had played in the NBA from its inception in 1946 to April 2015 (when we began the study). Players who only participated in the ABA league were excluded (299 cases), but players who participated in both NBA and ABA leagues were included. The ABA league was an alternative professional league from 1967 to 1976.

Players were identified from www.basketball-reference.com, which is one of the most comprehensive databases of basketball player information. Players were automatically linked to their height, playing position, place of birth, games, and minutes played in their NBA career, together with the date of their debut and last season played. Playing position was divided into the following categories: Center (C), Center-Forward (C-F), Forward-Center (C-F), Forward (F), Forward-Guard $(F-G)$, Guard-Forward (G-F), and Guard (G). These positions represent a proxy regarding the physical and technical features of players. Regarding place of birth, we differentiated between US and non-US players. The remaining variables of interest were manually recorded player by player. Data on handedness, weight, ethnicity, date of birth, and date of death were added to the database by two of the authors and three independent coders, who received prior training for that purpose. The number of deceased players before April 15, 2015 was 734.

\subsection{Validation of Variables: Height and Ethnicity}

We implemented a sequence of manual data entry using a validation process. In the first stage, researchers entered data on weight, date of birth, and date of death in a sample of 1620 cases.

Two trained coders (Coder 1 and Coder 2) then recorded the remaining cases (1178 and 1187, respectively), after which a third coder (Coder 3 ) validated the codification. The number of mismatches (disagreements) identified for these three variables was 72, 72, and 49, respectively. We reviewed and resolved all mismatches. Ethnicity was recorded by two independent coders and classified in three categories: African-American, White/Asian, and Mixed. Coders were trained to identify players who were born from parents with different ethnicity, such as Jason Kidd, Tony Parker, Blake Griffin or Aaron Gordon. Once this process was finished, all researchers reviewed the codification and discussed dubious cases. The final categorization was reached by consensus. Coding of handedness was also done manually by two of the authors without any recorded mismatches.

Registration of height required particular attention because differences were found from one source to another. While we initially collected the data from www.basketball-reference.com in April 2015, the height of 43 players had changed when the data were checked again in June 2017. To fix this divergence, we consulted www.NBA.com, where the heights recorded were similar to those obtained in June 2017 from www.basketball-reference.com (39 of 43 coincidences). We decided to use heights from NBA.com for all of these 43 players. The International Basketball Federation (FIBA) also reports the height of participating players; we identified 238 players from the FIBA website who were also in our database and found that the heights reported for FIBA tournaments varied for almost all cases. As there was no way to decide which of the sources was most reliable, we regressed FIBA heights on NBA heights for the 238 players identified and observed a statistically significant constant (7.040) and regression coefficient (0.964) (standard errors were bootstrapped), with an R-square of 0.953. Using these parameters, we estimated the heights of the remaining 3757 NBA players as a proxy of their FIBA height. Consequently, we had two different versions of the height variable.

Finally, having completed the codification and validation process, we investigated the cause of death of those 734 players using the Google search engine and specialist sources such as basketball networks (APBR), digital newspapers (New York Times, LA Times), sports websites (ESPN), and other media resources. Only 443 of the 734 deaths $(60.35 \%)$ could be clearly assigned to a cause. We codified 
every cause of death using the International Statistical Classification of Diseases and Related Health Problems 10th Revision (ICD-10)-WHO Version for 2016.

\subsection{Statistical Analysis}

For the descriptive analysis, we computed the means of absolute and relative frequencies for categorical variables of interest, and measures of central tendency and statistical dispersion for numeric variables.

To analyze survival times among NBA players, we studied two different response variables. First, survival time was defined as the time elapsed from the end of the NBA career until death. Players who were active on 15 April 2015 were excluded from this analysis, and the survival times of former players alive on 15 April 2015 were treated as right-censored. We estimated survival probabilities and median survival time using the Kaplan-Meier method [25]. We conducted multivariate analysis using the Cox proportional hazards model [26], whose measure of effect size is the hazard ratio, i.e., the ratio of instantaneous risk functions, which is assumed to be constant over time. The potential predictors were the players' physical characteristics and NBA career-related variables. In addition, the model was adjusted for age and year of the players' retirement from the NBA. For the second objective, age at death was modeled as the response variable; this analysis included both active and former players. The survival times of players who were alive on 15 April 2015 were treated as right-censored, and all survival times were treated as left-truncated at the age of the corresponding NBA debut. As before, survival probabilities were estimated using the Kaplan-Meier method and the multivariate analysis was conducted using the Cox proportional hazards model. The potential model predictors were the players' characteristics. In addition, the model was adjusted for the year of the players' first NBA season. Studying age at death permits us to estimate LE as the model-based estimate of the median. For both models, only African-American and white players were considered, and the proportional hazard assumptions of both models were checked using the Schoenfeld residuals [27].

Moreover, to compare the mortality of African-American and white NBA players with that of the general African-American and white US populations, respectively, we computed standardized mortality ratios (SMRs) for the years 2000 through 2014. This measure is the ratio of the observed to the expected number of deaths in the study population, where the yearly expected number of deaths was calculated based on the players' ages on January 1, and the survival probabilities of the same year in the corresponding population.

All analyses were conducted using version 3.4.4 of the R statistical software (Vienna, Austria; http:/ / www.rproject.org/). Specifically, we used the R packages survival [28] and epitools [29] to analyze the survival times and to compute the SMRs, respectively. The R code of the analyses carried out and the data are available as Supplemental Material. This work fulfils the transparency and reproducibility of scientific research.

\subsection{Ethical Considerations}

We did not seek ethical approval for this study, as all information used and reported is freely available via online sources.

\section{Results}

\subsection{Descriptive Analysis}

Table 1 presents characteristics of the players included in this study according to their status (active versus former NBA players), and the proportions all former players who died before 15 April 2015. The mean height and weight of players during this period were $198 \mathrm{~cm}$ (SD: 9.32) and $94.8 \mathrm{~kg}$ (SD: 12), respectively. A total of 1535 players (38.7\%) were White, 2324 (58.7\%) were African-American, and $103(2.6 \%)$ were mixed. Regarding player position, 11\% were centers, 
$4.53 \%$ center-forwards, $28.7 \%$ forwards, $8.3 \%$ forward-centers, $4.94 \%$ forward-guards, $34.3 \%$ guards, and $8.11 \%$ guard-forwards.

Table 1. Descriptive analysis of variables for active and former players, and players who died.

\begin{tabular}{|c|c|c|c|c|}
\hline & Total $^{1}$ & Active $^{1}$ & Former $^{1}$ & Players Who Died ${ }^{2}$ \\
\hline & $\mathrm{N}=3985$ & $\mathrm{~N}=481$ & $\mathrm{~N}=3504$ & $\mathrm{~N}=687$ \\
\hline \multicolumn{5}{|l|}{ Position } \\
\hline Center & $431(11.0 \%)$ & $53(11.3 \%)$ & $378(11.0 \%)$ & $70(18.52 \%)$ \\
\hline Center-Forward & 177 (4.53\%) & $11(2.35 \%)$ & $166(4.83 \%)$ & $51(30.72 \%)$ \\
\hline Forward & $1122(28.7 \%)$ & $146(31.1 \%)$ & $976(28.4 \%)$ & $163(16.7 \%)$ \\
\hline Forward-Center & $326(8.34 \%)$ & $32(6.82 \%)$ & $294(8.55 \%)$ & $84(28.57 \%)$ \\
\hline Forward-Guard & 193 (4.94\%) & $20(4.26 \%)$ & $173(5.03 \%)$ & $50(28.9 \%)$ \\
\hline Guard & $1342(34.3 \%)$ & $163(34.8 \%)$ & $1179(34.3 \%)$ & $178(15.1 \%)$ \\
\hline Guard-Forward & $317(8.11 \%)$ & $44(9.38 \%)$ & $273(7.94 \%)$ & $77(28.21 \%)$ \\
\hline \multicolumn{5}{|l|}{ Ethnicity } \\
\hline White & 1535 (38.7\%) & $112(23.3 \%)$ & $1423(40.9 \%)$ & $517(36.33 \%)$ \\
\hline Mixed & $103(2.60 \%)$ & 47 (9.79\%) & $56(1.61 \%)$ & $1(1.79 \%)$ \\
\hline African-American & $2324(58.7 \%)$ & $321(66.9 \%)$ & $2003(57.5 \%)$ & $165(8.24 \%)$ \\
\hline \multicolumn{5}{|l|}{ Place } \\
\hline Non-USA & $360(9.03 \%)$ & $100(20.8 \%)$ & $260(7.42 \%)$ & $12(4.62 \%)$ \\
\hline USA & $3625(91.0 \%)$ & $381(79.2 \%)$ & $3244(92.6 \%)$ & $675(20.81 \%)$ \\
\hline \multicolumn{5}{|l|}{ Left handed } \\
\hline No & $3753(94.2 \%)$ & $439(91.3 \%)$ & $3314(94.6 \%)$ & 661 (19.95\%) \\
\hline Yes & $232(5.82 \%)$ & $42(8.73 \%)$ & $190(5.42 \%)$ & $26(3.78 \%)$ \\
\hline Age-years-at debut (mean; SD) & $23.4(2.11)$ & $22.0(1.93)$ & $23.6(2.06)$ & $24.2(2.34)$ \\
\hline $\begin{array}{l}\text { Age-years-at end of the last NBA } \\
\text { season (mean; SD) }\end{array}$ & $28.2(4.36)$ & $27.4(4.21)^{3}$ & $28.3(4.37)$ & $27.8(3.56)$ \\
\hline Height-cm (mean; SD) & $198(9.32)$ & $201(8.75)$ & $198(9.34)$ & $194(8.81)$ \\
\hline Weight—kg (mean; SD) & $94.8(12.0)$ & $100(12.1)$ & $94.1(11.8)$ & $198(22.1)$ \\
\hline Number of NBA games (mean; SD) & $277(310)$ & $342(294)^{3}$ & $268(311)$ & $183(230)$ \\
\hline
\end{tabular}

${ }^{1}$ Percentages represent proportions of all, active, and former players, respectively; ${ }^{2}$ Percentages represent the number of players who died, as a proportion of all former players; ${ }^{3}$ These measures are not comparable because the active players are still playing.

\subsection{Survival Analysis}

We used the follow-up data for the 3504 former NBA players, of whom 687 (19.1\%) died before 15 April 2015, to study the time elapsed from the end of their NBA career until death.

The unadjusted nonparametric estimation of the survival function (Figure 1) shows that the estimated probability of survival to 67 years of age is about 0.15 . The estimated median survival time is 54.8 years ( $95 \%$ confidence interval, $95 \% \mathrm{CI}=53.7-55.9$ years). 


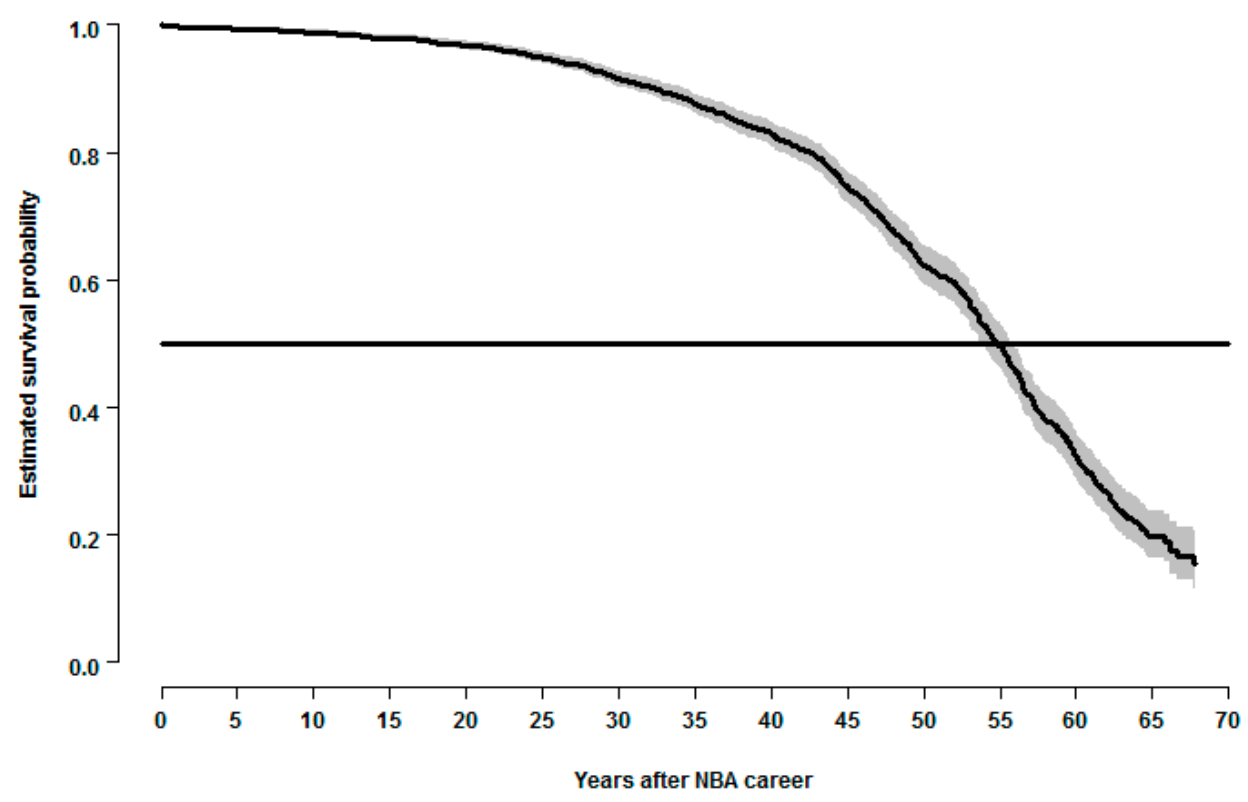

Figure 1. Estimated survival probabilities of former NBA players after their NBA career. The shaded area represents the $95 \%$ confidence bands, and the horizontal line represents survival probability of 0.5 .

Regarding age of death of NBA players, we analyzed data for all active and former players and computed an unadjusted nonparametric estimation of the survival function (Figure 2). The estimated median age at death was 81.3 years $(95 \% \mathrm{CI}=80.2-82.5$ years). The youngest NBA player to die was Nick Vanos, who was killed at the age of 24 years in an airplane crash. The oldest former NBA player was Ben Goldfadden, who died at the age of 99 years.

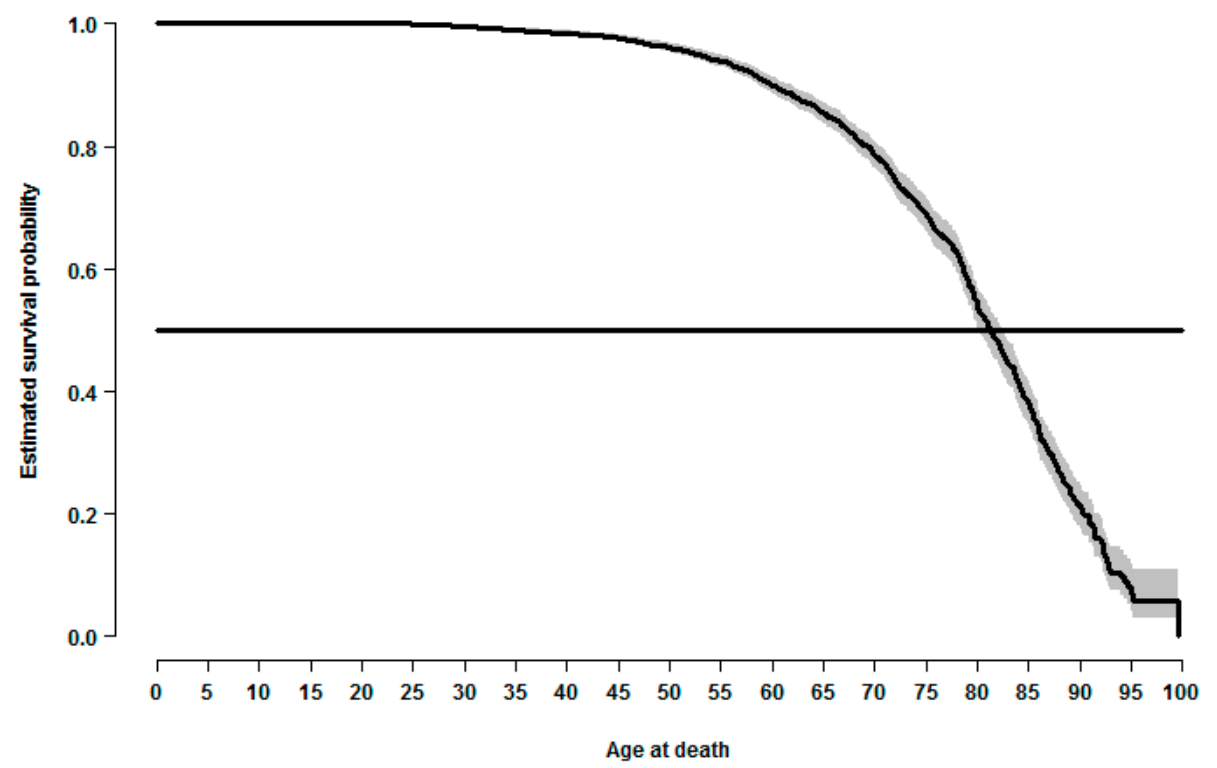

Figure 2. Estimated survival probabilities as a function of age of active and former NBA players. The shaded area represents the $95 \%$ confidence bands, and the horizontal line represents survival probability of 0.5 .

Table 2 presents the proportional hazards models for both response variables of interest; these models include all variables that were statistically significantly associated with the survival times of NBA players. According to both models, the height of NBA players is related to survival time. The positive sign of the estimated parameters indicates that instantaneous risk increases with 
increasing height. In addition, when comparing African-American players to white players, the estimated adjusted hazard ratio is 1.4 for both models, indicating higher instantaneous risk among African-American players. The increase in LE in recent decades is reflected in the negative sign of the parameter estimate for the variables for year of players' last (Model I) and first NBA seasons (Model II). The positive sign of the parameter estimate of the age variable at end of their NBA career (Model I) is expected because it reflects the fact that average survival time is longer the younger the player was when he finishes his career. However, it does not imply that this variable is related to age at death. Further NBA career-related variables, such as number of NBA games, which could have been included in Model I, were not statistically significant.

Table 2. Cox regression models to analyze factors associated with mortality among NBA players during the period 1946-2015. The response variable in Model I is the time elapsed from the end of the NBA career until death. The response variable in Model II is age at death.

\begin{tabular}{ccccc}
\hline Model I Variables & Estimate & SE & HR (95\% CI) & $p$-Value \\
\hline Height & 0.02 & 0.005 & $1.02(1.01-1.03)$ & $<0.001$ \\
Age at end of NBA career & 0.09 & 0.011 & $1.10(1.07-1.12)$ & $<0.001$ \\
Year of last NBA season & -0.02 & 0.005 & $0.98(0.97-0.99)$ & $<0.001$ \\
Ethnicity (African-Americans vs. White) & 0.35 & 0.113 & $1.41(1.13-1.76)$ & $<0.001$ \\
\hline Model II Variables & Estimate & SE & HR (95\% CI) & $p$-Value \\
\hline Height & 0.02 & 0.005 & $1.02(1.01-1.03)$ & $<0.001$ \\
Year of first NBA season & -0.02 & 0.005 & $0.98(0.97-0.99)$ & $<0.001$ \\
Ethnicity (African-Americans vs. White) & 0.31 & 0.109 & $1.37(1.11-1.69)$ & 0.002 \\
\hline
\end{tabular}

SE: Standard error; HR: Hazard ratio.

The analysis of the Schoenfeld residuals by means of R's cox.zph function revealed that the proportional hazards assumption holds reasonably well. In the case of Model I, the $p$-value corresponding to the null hypothesis of proportional hazards was 0.061 , and in the case of the Model II, it was 0.548. Model II models the age at death of NBA players and can be used to estimate the median survival time based on the variables included in the model, which can be interpreted as the players' LE. Table 3 shows the estimations ( $95 \%$ CI) for African-American and white NBA players of $2 \mathrm{~m}$ tall for different NBA debut years. It can be observed that the estimated LE of NBA players increased steadily throughout the last decades and that in 2010, it was 89 years for white NBA players and 85.8 years for African-American players.

Table 3. Estimated median ages (and 95\% confidence intervals) at death among NBA players of $2 \mathrm{~m}$ in height as a function of ethnicity and year of first NBA season.

\begin{tabular}{cccccc}
\hline Ethnicity & Height $\mathbf{( c m )}$ & Year & Median Age (Life Expectancy) & CI 95\% LI & CI 95\% LS \\
\hline White & 200 & 1950 & 79.6 & 78.6 & 81.0 \\
African-American & 200 & 1950 & 76.6 & 74.2 & 79.2 \\
White & 200 & 1960 & 81.0 & 79.7 & 82.6 \\
African-American & 200 & 1960 & 78.5 & 76.5 & 80.0 \\
White & 200 & 1970 & 82.8 & 80.6 & 85.1 \\
African-American & 200 & 1970 & 79.6 & 78.4 & 81.5 \\
White & 200 & 1980 & 84.3 & 81.7 & 87.8 \\
African-American & 200 & 1980 & 81.0 & 79.2 & 84.0 \\
White & 200 & 1990 & 85.9 & 82.6 & 91.2 \\
African-American & 200 & 1990 & 82.6 & 79.9 & 86.4 \\
White & 200 & 2000 & 87.4 & 83.7 & 94.3 \\
African-American & 200 & 2000 & 84.3 & 80.6 & 89.7 \\
White & 200 & 2010 & 89.0 & 84.5 & - \\
African-American & 200 & 2010 & 85.8 & 81.7 & 92.7 \\
\hline
\end{tabular}




\subsection{Comparison of Yearly Mortality Rates of NBA Players with the General Population}

Figure 3 shows the standard mortality ratios computed when comparing the age-adjusted mortality rates of African-American and white NBA players to those of the respective general US populations from 2000 through 2014. For almost all years analyzed, the SMRs are less than 1, implying that NBA players have lower mortality rates than the general population.

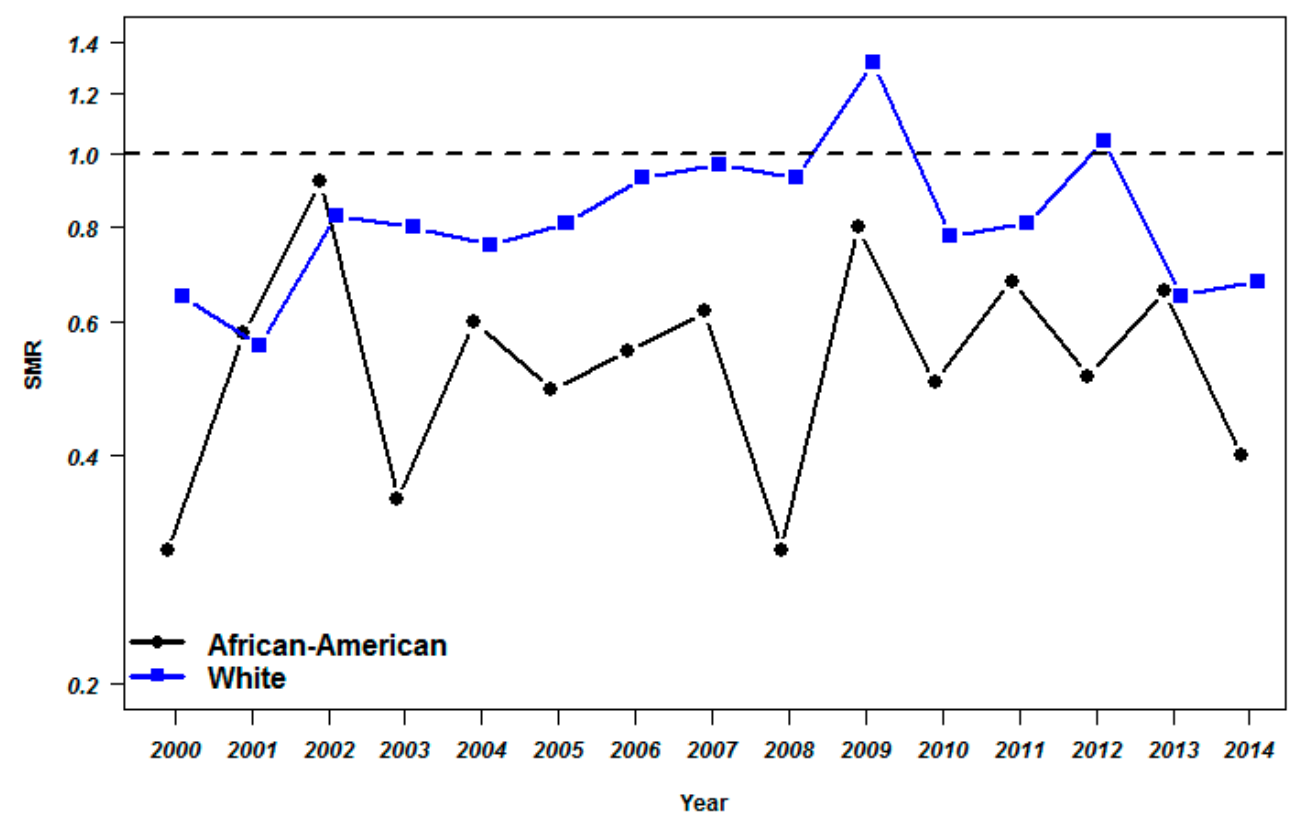

Figure 3. Standard mortality ratios between observed and expected mortality rates among AfricanAmerican and white NBA players, compared to their respective general US populations.

While most of SMRs for white players are close to 1, those for African-Americans are lower, with most values around 0.6, ranging from 0.3 (2000 and 2008) to 0.92 (2002); this represents a greater difference in mortality with respect to the general African-American population.

\section{Discussion}

We analyzed factors associated with mortality among NBA players and compared the LE of NBA players to that in the general population. To achieve this aim, we analyzed data from the 3985 players who participated in the NBA from its inception in 1946 to April 2015.

After adjusting for age at the end of the season and calendar year, we found that mortality is associated with height and ethnicity. Taller players and African-American players have a higher instantaneous death risk than smaller or white players. In addition, overall instantaneous risk of death has decreased over time because players' LE has increased since the inception of the NBA, regardless of height and ethnicity.

However, for the same height and time period, we observed differences between the LE of white and African-American players (Table 3). African-American players have lower mortality than the general African-American population. There were differences for at least in four of the years between 2000 and 2014, and a trend is also evident (Figure 3).

The mortality risk of African-American players in this cohort was lower than that of the general US African-American male population, and it is not obvious why this healthy worker effect (HWE) [30] is only seen in African-American players. Recall that HWE refers to the tendency of the actively employed to have a more favorable mortality experience than the population at large.

The reason may be related to the progressive equalization of wages between African-American and white NBA players. There have been reports on ethnicity-based salary discrimination in professional 
basketball, where African-American players were paid less than white players for similar levels of performance [31]. However, results from this study indicate reported that the NBA has equitable treatment for players of both ethnicities, at least with regard to veteran free agents, as reported previously [32].

This finding contrasts with the wage gap between African-American and white workers in the general population, which grew from $16.9 \%$ in 1979 to $22.5 \%$ in 2014 [33]. The relative "ethnicity advantage" of African-American players with respect to the general African-American population is thought to be partly due to salary, owing to the known impact of wage on socioeconomic status (SES). Nonetheless, while SES is the most important factor, it is not the only one that explains racial differences in mortality [34].

The significant effect of ethnicity on mortality could therefore be partly explained by historical salary differences between African-American and white players, at least up to the mid-1980s [31,35]. The effect of wage equalization on players' instantaneous risk of death should be evaluated again in the future when data on the mortality of players who played from the mid-1980s onwards become available); notably, the "racial" salary gap has started to grow again since 2006 [35].

However, it is also possible that other features related to ethnicity could affect death risk. For example, the authors of [36] commented on the results from the study of 566 NBA players carried out by Engel et al. [9]. Left ventricular hypertrophy (LVH) was observed in $27.4 \%$ of athletes, with ethnicity identified as a key determinant of the prevalence and geometric pattern of LVH (more prevalent in African-American players). Marked changes in electrocardiographic repolarization have also been demonstrated in athletes of African-American ethnicity [37].

Further, African-American players have a significantly higher likelihood of dying from cardiac disease than white players [38]. Although of great interest, the conclusions derived by Engel et al. contribute to a framework to help to avoid unnecessary exclusion of athletes from competition, rather than to predicting further negative health outcomes [9]. Therefore, factors associated with mortality of basketball players following heart events are still a topic of interest.

While most studies find that taller people have lower rates of CVD than shorter people [39], it is also evident than a notable number of NBA players suffer from heart problems. For example, Larry Bird was diagnosed with atrial fibrillation in 1995, and current players LaMarcus Aldridge, Jeff Green, and Channing Frye have had heart issues [16]. Indeed, increasing height is an independent risk factor for atrial fibrillation, and measured and genetically determined height have been reported to be significantly associated with PR interval and QRS duration [40].

Regarding respiratory diseases, height is a positive predictor of emphysema in patients with chronic obstructive pulmonary disease [41], although conversely, height was found to be inversely associated with mortality [42,43].

Our study has also confirmed that height is positively associated with mortality, as other studies have previously shown [13,38]). Lemez et al. did not find substantive variability in the causes of death between basketball players and the general population [38], highlighting the need for further work. As previously mentioned, height has been found to be positively associated with cancer risk and negatively associated with CVD in other populations [10-12]. Better understanding of the special features of basketball players regarding height is needed to analyze the relationship with diseases, most notably CVD, because height is an independent risk factor for atrial fibrillation [40]. While height has been inversely associated with CVD in many studies, numerous basketball players suffer from heart problems and have high risk of sports-related SCD and PE.

However, it has been found that elite and team athletes of aerobic-anaerobic sports live longer than the general population $[19,20]$. This apparent contradiction between positive and negative factors highlights the need to better understand the causes of mortality in retired basketball players and their LE compared with the general population.

It is also important to mention that the remaining covariables considered when estimating the models were not relevant. Handedness was a special interest because some studies have shown that 
left-handers have lower longevity than right-handers [44]. However, our results do not support this relationship, as another study has also found [39].

Our Model II makes predictions about the LE of NBA players. For example, the estimated median age at death for former NBA players with characteristics similar to Larry Bird's (height $=205.74 \mathrm{~m}$, white NBA player, and NBA debut in 1979) is 82.8 years (95\% CI: 80.1-86).

\subsection{Limitations and Strengths}

The main limitation of our study is the limited knowledge about the life-history of players once they retire. It is well known that some remain active with a healthy lifestyle, while others gain excessive weight. In addition, we did not have access to disease or family data nor the clinical history of the players. Therefore, our results are only suggestive about a general association between mortality and height and ethnicity.

We considered the number of games played as a proxy to measure the volume of exercise, but we do not have tracking data that can inform about the intensity, load or density of exercise. We also had information about the number of minutes played and the number of minutes per game played, but all three variables were highly correlated. Further, we had missing data of minutes played for 344 players, so we only analyzed the number of games played. Very extreme or very intense exercise has been related to mortality [24], but we did not find any association between the number of games played and risk of death. However, many of the players in our sample had careers outside the NBA, playing in other leagues inside and outside United States. While some of these competitions are also very demanding (especially the major European competitions), the level of physical requirement is lower than that for the NBA. However, this absent information was a shortcoming for our analysis.

A considerable percentage of games in the NBA are considered as "close games" [45], where home/away teams are winning by less than 10 points at the end of the 3rd quarter. Specifically, we explored a large data base provided by www.nbastuffer.com; a sample of 2623 regular season and play-off games between 2009 and 2011. The percentage of "close games" was 52.2\%. This probably means that the distribution of close games in our whole sample is not homogenous, but these claims should be tested in further research with more comprehensive data. It is known that emotional stressors trigger cardiovascular events [46], but literature has also shown that high drama/intensity experience lived by sports fans can be associated with changes in cardiovascular death rates in the short term, depending on winning (decrease) or losing (increase) [47]. Therefore, it is not clear how highly intense, mentally demanding games in the NBA could influence mortality in the long term, considering the possible moderating factor of winning vs. losing close games. In addition, divergences in intensity between players are not related to the risk of all-cause mortality [48], as has been suggested after comparing National Football League participation as a career player with participation as a replacement player.

Finally, regarding ethnicity, we recognize the complexity of considering this variable in our analysis. As Pedro Gómez pointed out, we have thousands of genes that are invisible except for a few anatomical features such as skin color [49], so categorizing individuals only for one visible feature could be deemed crude. We followed the example of other studies that used the simplistic categorization of White versus African-American using skin color [9]. However, we took precautions to carefully consider and eliminate "mixed ethnicity" from the analysis, in order to take into account players with white and African-American parents (56, 1.6\%).

The aim of our study was to analyze overall mortality, but not specific mortality, as Lemez et al. recently did [38]. This requires advanced survival analysis, such as the competing risk method, to analyze the causes of death. However, we believe it would be necessary to reduce the number of missing cases. Lemez et al. [38] had 34.7\% of missing cases and in a search, we obtained $39.6 \%$ of missing cases. However, it is difficult to know the causes of death of players where information is not available from public sources. 
Regarding methodological considerations, we analyzed survival time, rather than a dichotomous response variable (alive or dead). Moreover, we considered the age at death of NBA players to estimate LE. Finally, we used SMRs to compare the mortality of African-American and white NBA players with that in the general African-American and white US population.

\subsection{Practical Implications}

Evaluating mortality among NBA players will be useful for devising strategies for health interventions and the proper allocation of resources with respect to the general population.

In 2015, players' associations began to increase their efforts to offer cardiac screening and to raise awareness about the incidence of these diseases among retired players [50]. The NBA also began to provide information on healthy practices that could help improve their overall health status.

\section{Conclusions}

Mortality among NBA players was associated with ethnicity and height. White players and small players live longer. In addition, NBA players have a lower instantaneous risk of death than the general US population. This difference is especially notable among African-American players, with respect to the US African-American population.

Supplementary Materials: The following are available online at http:/ /www.mdpi.com/2076-3417/9/3/500/s1.

Author Contributions: All authors contributed to the paper. Conceptualization, J.A.M. and M.C.; Data curation, J.A.M., J.F. and M.C.; Formal analysis, K.L. and M.C.; Project administration, J.A.M. and M.C.; Resources, J.A.M.; Supervision, J.A.M., K.L., J.F. and M.C.; Validation, J.A.M. and M.C.; Visualization, K.L.; Writing-original draft, J.A.M., K.L. and M.C.; Writing-review and editing, J.A.M., K.L., J.F. and M.C.

Funding: J.A.M. acknowledges the financial support from project ECO2015-65637-P (MINECO/FEDER). K.L. acknowledges the financial support from project MTM2015-64465-C2-1-R (MINECO/FEDER). This study is the result of the activity carried out under the program Groups of Excellence of the region of Murcia, the Fundación Séneca, Science and Technology Agency of the region of Murcia project 19884/GERM/15.

Conflicts of Interest: None of the authors have any conflict of interest to declare.

\section{References}

1. Fortington, L.V.; Finch, C.F. Death in community Australian football: A ten year national insurance claims report. PLoS ONE 2016, 11, e0159008. [CrossRef] [PubMed]

2. Fortington, L.V.; Bekker, S.; Finch, C.F. Online news media reporting of football-related fatalities in Australia: A matter of life and death. J. Sci. Med. Sport 2018, 21, 245-249. [CrossRef] [PubMed]

3. Lemez, S. Mortality in Professional Athletes: Examining Incidence, Predictors and Causes of Death. Ph.D. Thesis, York University, York, UK, 2015.

4. Lemez, S.; Baker, J. Do Elite Athletes Live Longer? A Systematic Review of Mortality and Longevity in Elite Athletes. Sports Med. Open 2015, 1, 1-14. [CrossRef] [PubMed]

5. Radonić, V.; Kozmar, D.; Počanić, D.; Jerkić, H.; Bohaček, I.; Letilović, T. Mortality and causes of death among Croatian male Olympic medalists. Croat. Med. J. 2017, 58, 263-269.

6. Sarna, S.; Sahi, T.; Koskenvuo, M.; Kapiro, J. Increased life expectancy of world class male athletes. Med. Sci. Sports Exerc. 1993, 25, 237-244. [CrossRef] [PubMed]

7. Fafian, J.J. Mortality experience of National Association Players. N. Am. Actuar. J. 1997, 1, 45-48. [CrossRef]

8. Lawler, T.P.; Lawler, F.; Gibson, J.; Murray, R. Does the African-American-White Mortality Gap Persist After Playing Professional Basketball? A 59-Year Historical Cohort Study. Ann. Epidemiol. 2012, 22, 406-412. [CrossRef] [PubMed]

9. Engel, D.J.; Schwartz, A.; Homma, S. Athletic cardiac remodeling in US professional basketball players. JAMA Cardiol. 2016, 1, 80-87. [CrossRef]

10. Kabat, G.C.; Anderson, M.L.; Heo, M.; Hosgood, H.D., 3rd; Kamensky, V.; Bea, J.W.; Hou, L.; Lane, D.S.; Wactawski-Wende, J.; Manson, J.E.; et al. Adult Stature and Risk of Cancer at Different Anatomic Sites in a Cohort of Postmenopausal Women. Cancer Epidemiol. Biomarkeers Prev. 2013, 22, 1353-1363. [CrossRef] [PubMed] 
11. Khankari, N.K.; Shu, X.O.; Wen, W.; Kraft, P.; Lindström, S.; Peters, U.; Schildkraut, J.; Schumacher, F.; Bofetta, P.; Risch, A.; et al. Colorectal Transdisciplinary Study (CORECT); Discovery, Biology, and Risk of Inherited Variants in Breast Cancer (DRIVE); Elucidating Loci Involved in Prostate Cancer Susceptibility (ELLIPSE); Transdisciplinary Research in Cancer of the Lung (TRICL). Association between Adult Height and Risk of Colorectal, Lung, and Prostate Cancer: Results from Meta-analyses of Prospective Studies and Mendelian Randomization Analyses. PLoS Med. 2016, 13, e1002118.

12. Sawada, N.; Wark, P.A.; Merritt, M.A.; Tsugane, S.; Ward, H.A.; Rinaldi, S.; Weiderpass, E.; Dartois, L.; His, M.; Boutron-Ruault, M.C.; et al. The association between adult attained height and sitting height with mortality in the European Prospective Investigation into Cancer and Nutrition (EPIC). PLoS ONE 2017, 12, e0173117. [CrossRef] [PubMed]

13. Samaras, T.T. How height is related to our health and longevity: A review. Nutr. Health 2012, 21, $247-261$. [CrossRef] [PubMed]

14. Lutsea, P.L.; Folsom, A.R. Taller women are at greater risk of recurrent venous thromboembolism: The Iowa Women's Health Study. Am. J. Hematol. 2012, 87, 716-717. [CrossRef] [PubMed]

15. Casals, M.; Martínez, J.A.; Cayla, J.; Martín, V. Do Basketball Players Have a High Risk of Pulmonary Embolism? A Scoping Review. Med. Sci. Sports Exerc. 2016, 48, 466-471. [CrossRef] [PubMed]

16. MacMullan, J. Larry Bird Will Die Young. Available online: http://www.espn.com/nba/story/_/id/ 14712117 / larry-bird-believes-nba-big-men-dieyoung-right (accessed on 4 February 2018).

17. Spears, M.J. The NBA Seeks to Address a Spiking Problem with Heart Disease. Available online: https:// theundefeated.com/features/the-nba-seeksto-address-a-spiking-problem-with-heart-disease/ (accessed on 4 February 2018).

18. Teramoto, M.; Bungum, T.J. Mortality and longevity of elite athletes. J. Sci. Med. Sport 2010, 13, 410-416. [CrossRef] [PubMed]

19. Garatachea, N.; Santos-Lozano, A.; Sanchis-Gomar, F.; Fiuza-Luces, C.; Pareja-Galeano, H.; Emanuele, E.; Lucia, A. Elite athletes live longer than the general population: A meta-analysis. Mayo Clin. Proc. 2014, 89, 1195-1200. [CrossRef] [PubMed]

20. Kettunen, J.A.; Kujala, U.M.; Kaprio, J.; Bäckmand, H.; Peltonen, M.; Eriksson, J.G.; Sarna, S. All-cause and disease-specific mortality among male, former elite athletes: An average 50-year follow-up. Br. J. Sports Med. 2015, 49, 893-897. [CrossRef]

21. Kontro, T.K.; Sarna, S.; Kaprio, J.; Kujala, U.M. Mortality and health-related habits in 900 Finnish former elite athletes and their brothers. Br. J. Sports Med. 2018, 52, 85-95. [CrossRef] [PubMed]

22. O’Donovan, G.; Lee, I.M.; Hamer, M.; Stamatakis, E. Association of "Weekend Warrior" and Other Leisure Time Physical Activity Patterns with Risks for All-Cause, Cardiovascular Disease, and Cancer Mortality. JAMA Intern. Med. 2017, 177, 335-342. [CrossRef]

23. Gleason, P.T.; Kim, J.H. Exercise and Competitive Sport: Physiology, Adaptations, and Uncertain Long-Term Risks. Curr. Treat. Options Cardiovasc. Med. 2017, 19, 79. [CrossRef]

24. Kim, J.H.; Baggish, A.L. Strenuous exercise and cardiovascular disease outcomes. Curr. Atheroscler. Rep. 2017, 19, 1. [CrossRef] [PubMed]

25. Kaplan, E.L.; Meier, P. Nonparametric Estimation from Incomplete Observations. J. Am. Stat. Assoc. 1958, 53, 457-481. [CrossRef]

26. Cox, D.R. Regression Models and Life-Tables. Journal of the Royal Statistical Society. Ser. B (Methodol.) 1972, 34, 187-220. [CrossRef]

27. Grambsch, P.M.; Therneau, T.M. Proportional hazards tests and diagnostics based on weighted residuals. Biometrika 1994, 81, 515-526. [CrossRef]

28. Therneau, T. A Package for Survival Analysis in S. Version 2.43-3. 2018. Available online: https:/ /CRAN.Rproject.org / package=survival (accessed on 30 January 2019).

29. Aragon, T.J. Epitools: Epidemiology Tools. R Package Version 0.5-10. 2017. Available online: https:/ /CRAN. R-project.org/package=epitools (accessed on 30 January 2019).

30. Lincoln, A.E.; Vogel, R.A.; Allen, T.W.; Dunn, R.E.; Alexander, K.; Kaufman, N.D.; Tucker, A.M. Risk and causes of death among former National Football League players (1986-2012). Med. Sci. Sports Exerc. 2018, 50, 486-493. [CrossRef] [PubMed]

31. Jenkins, J.A. A reexamination of salary discrimination in professional basketball. Soc. Sci. Q. 1996, 77, 594-608. 
32. Gius, M.; Johnson, D. An empirical investigation of wage discrimination in professional basketball. Appl. Econ. Lett. 1998, 5, 703-705. [CrossRef]

33. Wilson, V.; Rodgers, W.M., III. Black-White Wage Gaps Expand with Rising Wage Inequality; Economic Policy Institute: Washington, DC, USA, 20 September 2016.

34. Thorpe, R.J., Jr.; Koster, A.; Bosma, H.; Harris, T.B.; Simonsick, E.M.; van Eijk, J.T.; Kempen, G.I.; Newman, A.B.; Satterfield, S.; Rubin, S.M.; et al. Health ABC Study. Racial differences in mortality in older adults: Factors beyond socioeconomic status. Ann. Behav. Med. 2012, 43, 29-38.

35. Naito, H.; Takagi, Y. Is racial salary discrimination disappearing in the NBA? evidence from data during 1985-2015. Int. Rev. Appl. Econ. 2017, 31, 651-669. [CrossRef]

36. Baggish, A.L. Cardiac variables in professional basketball players: Looking closely at the normal big athlete (NBA). JAMA Cardiol. 2016, 1, 87-88. [CrossRef]

37. Chandra, N.; Papadakis, M.; Sharma, S. Cardiac adaptation in athletes of black ethnicity: Differentiating pathology from physiology. Heart 2012, 98, 1194-1200. [CrossRef] [PubMed]

38. Lemez SWattie, N.; Lawler, T.; Baker, J. Vital statistics and early death predictors of North American professional basketball players: A historical examination. J. Sports Sci. 2017, 36, 1648-1655. [CrossRef] [PubMed]

39. Paajanen, T.A.; Oksala, N.K.J.; Kuukasjarvi, P.; Karhunen, P.J. Short stature is associated with coronary heart disease: A systematic review of the literature and a meta-analysis. Eur. Heart J. 2010, 31, 1802-1809. [CrossRef] [PubMed]

40. Kofler, T.; Thériault, S.; Bossard, M.; Aeschbacher, S.; Bernet, S.; Krisai, P.; Blum, S.; Risch, M.; Risch, L.; Albert, C.M.; et al. Relationships of Measured and Genetically Determined Height with the Cardiac Conduction System in Healthy Adults. Circul. Arrhythmia Electrophysiol. 2016, 10, e004735. [CrossRef] [PubMed]

41. Miniati, M.; Bottai, M.; Pavlickova, I.; Monti, S. Body height as risk factor for emphysema in COPD. Sci. Rep. 2016, 22, 36896. [CrossRef] [PubMed]

42. Leon, D.A.; Smith, G.D.; Shipley, M.; Strachan, D. Adult height and mortality in London: Early life, socioeconomic confounding, or shrinkage? J. Epidemiol. Community Health 1995, 49, 5-9. [CrossRef] [PubMed]

43. Davey Smith, G.; Hart, C.; Upton, M.; Hole, D.; Gillis, C.; Watt, G.; Hawthorne, V. Height and risk of death among men and women: Aetiological implications of associations with cardiorespiratory disease and cancer mortality. J. Epidemiol. Community Health 2000, 54, 97-103. [CrossRef] [PubMed]

44. Ramadhani, M.K.; Elias, S.G.; van Noord, P.A.; Grobbee, D.E.; Peeters, P.H.; Uiterwaal, C.S. Innate handedness and disease-specific mortality in women. Epidemiology 2007, 18, 208-212. [CrossRef] [PubMed]

45. Gomez, M.A.; Gasperi, L.; Lupo, C. Performance analysis of game dynamics during the 4th game quarter of NBA close games. Int. J. Perform. Anal. Sport 2016, 16, 249-263. [CrossRef]

46. Schwartz, B.G.; French, W.J.; Mayeda, G.S.; Burstein, S.; Economides, C.; Bhandari, A.K.; Cannom, D.S.; Kloner, R.A. Emotional stressors trigger cardiovascular events. Int. J. Clin. Pract. 2012, 66, 631-639. [CrossRef]

47. Schwartz, B.G.; McDonald, S.A.; Kloner, R.A. Super Bowl outcome's association with cardiovascular death. Clin. Res. Cardiol. 2013, 102, 807-811. [CrossRef] [PubMed]

48. Venkataramani, A.S.; Gandhavadi, M.; Jena, A.B. Association Between Playing American Football in the National Football League and Long-term Mortality. JAMA 2018, 319, 800-806. [CrossRef] [PubMed]

49. Gómez, P. No hay Razas Humanas, pero Abundan los Racistas. Ensayos de Filosofía. 2016, 4 (2), Artículo 6. Available online: http://www.ensayosfilosofia.es/archivos/articulo/no-hay-razas-pero-abundan-losracistas (accessed on 10 January 2018).

50. Dent, M. Moses Malone, Darryl Dawkins and the Scary Trend That's Killing So Many Legendary NBA Bigs. Available online: https:/ / billypenn.com/2015/10/01/moses-malone-darryl-dawkins-and-the-scary-trendthats-killing-so-many-legendary-nba-bigs / (accessed on 20 May 2018).

(C) 2019 by the authors. Licensee MDPI, Basel, Switzerland. This article is an open access article distributed under the terms and conditions of the Creative Commons Attribution (CC BY) license (http://creativecommons.org/licenses/by/4.0/). 